\title{
Wind-induced, cross-frontal exchange on Georges Bank: A mechanism for early summer on-bank biological particle transport
}

\author{
Changsheng Chen, ${ }^{1}$ Ronald J. Schlitz, ${ }^{2}$ R. Gregory Lough, ${ }^{2}$ Keston W. Smith, ${ }^{3}$ \\ Robert Beardsley, ${ }^{4}$ and James P. Manning ${ }^{2}$ \\ Received 22 February 2002; revised 15 February 2003; accepted 6 June 2003; published 29 November 2003.
}

[1] Water exchange across the tidal-mixing front on the southern flank of Georges Bank (GB) is examined using a two-dimensional (2D) primitive equation ocean model. The model domain features a cross-frontal transect including a June 1999 hydrographic (CTD)/ADCP study made as part of the U.S. GLOBEC Northwest Atlantic/Georges Bank program. The model was initialized with temperature and salinity fields taken on the 15 June 1999 CTD section and run prognostically with tidal forcing, measured winds, and representative surface heat flux. The results show that fluctuations of wind plus tidal mixing can play the following essential role in the short-term transport of water and particles from the stratified region to the mixed region on GB in early summer, when stratification is just developing with a weak thermocline at a depth of about $10 \mathrm{~m}$. First, a passing weather front drives a wind-induced on-bank Ekman transport of the upper part of the water column at the tidal-mixing front and associated particles in the surface mixed layer. Then, when the wind relaxes or changes direction, the water in the on-bank extension of the front (above the thermocline) mixes quickly through enhanced tidal motion in shallower depths of water. As a result, particles that are advected along the extended front stay in the previously wellmixed region of the bank. Surface heating tends to increase the strength of the thermocline and reduce the thickness of the surface mixed layer. This in turn accelerates the on-bank movement of the front under an easterly wind favorable for Ekman transport and thus enhances the on-bank, cross-frontal transport of particles. Since the wind-induced, crossfrontal on-bank transport of water can occur episodically during passages of meteorological fronts, these could produce a larger net cross-frontal flux than that produced by just tidal forcing on equivalent timescales. Therefore wind-induced processes can be important in the on-bank cross-frontal flux of copepods and other zooplankton species that exhibit shallow maxima in their vertical distributions over the southern flank of GB in early summer. INDEX TERMS: 4528 Oceanography: Physical: Fronts and jets; 4568 Oceanography: Physical: Turbulence, diffusion, and mixing processes; 4842 Oceanography: Biological and Chemical: Modeling; 4572 Oceanography: Physical: Upper ocean processes; KEYWORDS: cross-frontal exchange, tidal mixing front, wind-driven currents

Citation: Chen, C., R. J. Schlitz, R. G. Lough, K. W. Smith, R. Beardsley, and J. P. Manning, Wind-induced, cross-frontal exchange on Georges Bank: A mechanism for early summer on-bank biological particle transport, J. Geophys. Res., 108(C11), 8011, doi:10.1029/2002JC001358, 2003.

\section{Introduction}

[2] Physical mechanisms responsible for the cross-frontal transport of water over Georges Bank (GB) have received intensive attention recently in the U.S. Global Ecosystem

\footnotetext{
${ }^{1}$ School of Marine Sciences and Technology, University of Massachusetts-Dartmouth, New Bedford, Massachusetts, USA

${ }^{2}$ Northeast Fisheries Sciences Center, Woods Hole, Massachusetts, USA.

${ }^{3}$ Numerical Methods Laboratory, Thayer School of Engineering, Dartmouth College, Hanover, New Hampshire, USA.

${ }^{4}$ Department of Physical Oceanography, Woods Hole Oceanographic Institution, Woods Hole, Massachusetts, USA.

Copyright 2003 by the American Geophysical Union. 0148-0227/03/2002JC001358\$09.00
}

(GLOBEC) Northwest Atlantic/Georges Bank Program [Anonymous, 1992]. Chen and Beardsley [1998] used a two-dimensional (2D) primitive equation model to examine the physical processes controlling the cross-frontal residual Lagrangian flow. They found a near-bottom, cross-frontal, on-bank transport of water in the bottom boundary layer resulting from asymmetric tidal mixing and strong nonlinear interaction (Stokes' drift). This finding was further amplified by Pringle and Franks [2001] using a simple analytical bottom boundary layer model. Both studies suggested that most of the near-bottom, cross-frontal, on-bank nutrient fluxes on GB are driven by asymmetric tidal mixing in the bottom boundary layer. Near-bottom, on-bank movement of water was also detected in model results by Loder et al. [1997]. On the basis of three-dimensional (3D) 
Lagrangian particle trajectories in the barotropic flow field, they found that the Stokes' drift on GB is comparable in magnitude to the Eulerian residual flow. This tends to cause an on-bank flux of water near the bottom.

[3] Chen et al. [2003a] recently examined the characteristics of the cross-frontal movement of water over GB by tracking particles in the $3 \mathrm{D}$ flow predicted prognostically with a primitive equation, turbulence-closure ocean model (ECOM-si [Blumberg, 1994]), using an initial condition of bi-monthly climatological stratification. The modeling results reveal two distinct pathways for on-bank, crossfrontal mean flow. One is at the western end of the northern flank of GB where the bottom topography changes sharply in both slope and direction. The other is near the bottom around the bank where the tidal-mixing front is located, generally near the $60-\mathrm{m}$ isobath. On the northern flank, strong nonlinearity causes a significant upward Stokes' velocity over steep bottom topography, which results in a net on-bank, cross-frontal transport of water near the bottom [Loder et al., 1997; Chen and Beardsley, 1998]. On the southern flank, water near the bottom tends to converge toward the tidal mixing and shelfbreak fronts, respectively, leading to a divergence zone on the outer flank within the cold band during vertical stratification [Chen et al., 1995]. Houghton and Ho [2001], in tracer experiments using fluorescent dye, detected a residual Lagrangian flow of roughly $1.9 \mathrm{~cm} / \mathrm{s}$ near the bottom on the southern flank toward the tidal-mixing front. It seems that the model results are in reasonable agreement with the tracer observations, suggesting again that the on-bank flow over GB is driven by stratified tidal rectification over variable bottom topography.

[4] The influence of winds on the cross-frontal transport of phytoplankton has received intensive attention in the last decade. Franks and Walstad [1997] found that transient winds aligned with or against a frontal jet tend to deepen or shoal the mixed layer and cause near-inertial oscillations. These frontal responses could lead to a nutrient flux across the pycnocline at the density front. For the same total windinduced momentum flux at the surface, Lewis et al. [2001] showed that the movement of a phytoplankton patch on GB differs significantly between constant and time-varying wind stress. Hannah et al. [1998] included a random walk process into particle tracking in their Gulf of Maine/GB modeling. Tracking particles in a Lagrangian velocity field derived from a small perturbation theory showed that the on-bank transport of biota is sensitive to the relative magnitude of vertical velocity to the diffusion-induced random walk velocity. Chen et al. [2003a] also explored the response of passive particles in the frontal zone to wind stress. They found that strong winds in winter tend to drive a considerable off-bank water transport, while the mean wind in summer is generally too weak to alter the general pattern of tidally-driven, along-frontal particle motion in the presence of a surface-to-bottom tidal-mixing front.

[5] During a cruise on board R/V Edwin Link to service moorings in early June 1999, CTD surveys were made to determine the location of the tidal-mixing front and hydrographic conditions over the southern flank of GB (Figure 1). A temperature/salinity transect made on 15 June clearly showed the tidal-mixing front centered at the 62-m isobath with a thermocline between 10 and $20 \mathrm{~m}$ below the surface in the stratified region (Figure 2). Westward wind was

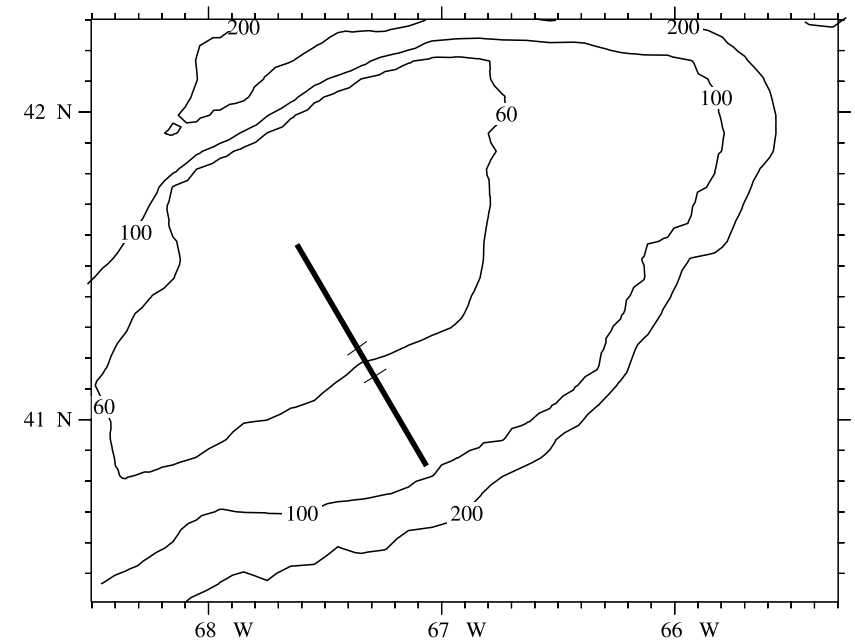

Figure 1. Map of Georges Bank showing location of the hydrographic (CTD) transect conducted on 15 June 1999 and the cross-bank section chosen for the model studies. Locations of the CTD section is only a portion of the section bounded by two crossing lines.

recorded on the ship during this time. The direction remained steady for three days, turned northward on 18 June, and then southward on 20 June, as a low pressure system passed near the bank (Figure 3).

[6] These observations raised the following questions. How do wind fluctuations affect the cross-frontal water exchange on the southern flank of GB in early summer when a thin thermocline develops? What are the roles of tidal mixing, advection, winds, and surface heat flux on the cross-frontal flux of the biota and particles on the southern flank in early summer? A preliminary examination of these two questions was made during the cruise using a 2D primitive equation model installed on the ship. The modeling suggested that the cross-frontal exchange of water on GB in early summer could occur intermittently on a timescale of 5-7 days coincident with surface wind stress fluctuations during storms and atmospheric frontal passages. This cross-frontal transport happened in two steps. First, the wind-induced Ekman transport tended to push both the upper part of the front and associated particles toward shallower water on GB. Then enhanced tidal mixing at decreased depths caused the water in the on-bankextended part of the front to become vertically mixed, trapping particles in the shallower mixed region.

[7] This paper presents a more detailed investigation of how wind and tidal mixing can combine to cause an enhanced transport of water and biota across the tidalmixing front on the southern flank of Georges Bank during summer. The model is described next, followed by model results, discussion, and conclusions.

\section{Model}

[8] The 2D model used here is a modified version of the GB model developed by Chen and Beardsley [1995] (C\&B). This GB model is a simplified version of the 3D semi-implicit estuarine and coastal ocean model (ECOM-si) developed by Blumberg [1994]. The model features a cross- 

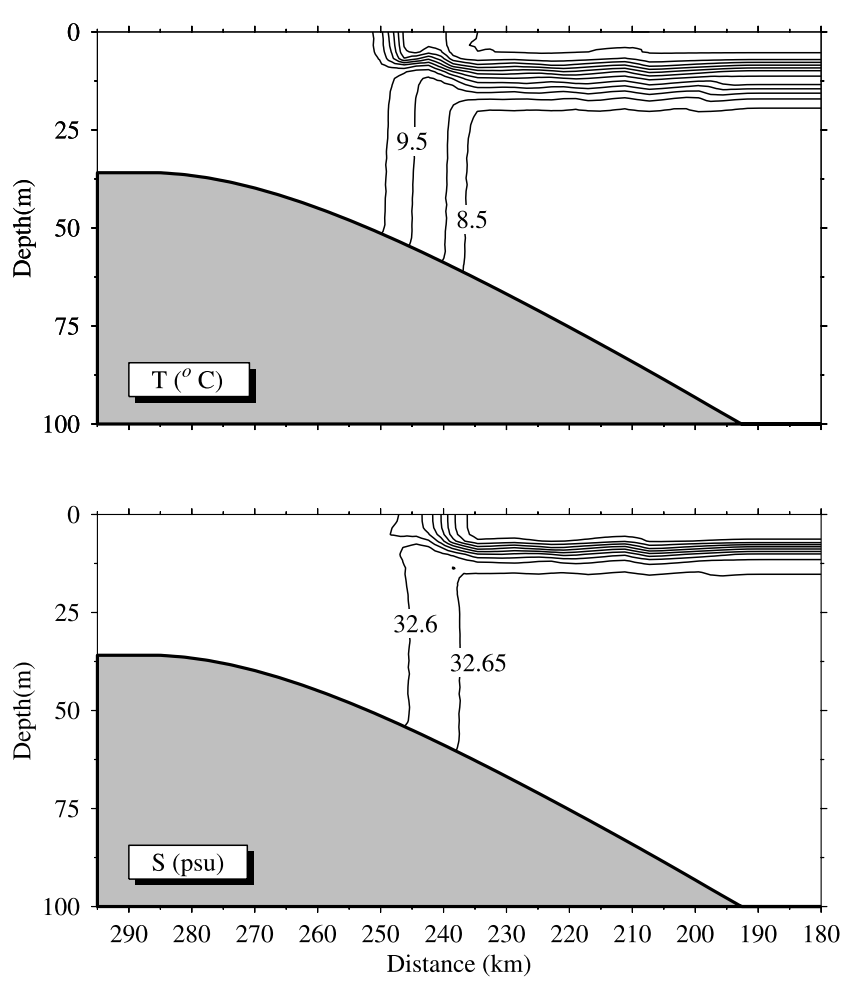

Figure 2. Cross-bank distributions of temperature and salinity on the southern flank on 15 June 1999, extended from the CTD section to the model domain.

bank section from southeast to northwest across the center of GB, with water depth varying from $300 \mathrm{~m}$ off the bank to $100 \mathrm{~m}$ at the southern shelf break and then gradually decreasing to $40 \mathrm{~m}$ at the northern edge of the bank. The model uses the $\sigma$-coordinate transformation defined by $\sigma=$ $(z-\zeta) /(H+\zeta)$ where $\mathrm{z}$ is the vertical axis, $\zeta$ is the surface elevation, and $H$ is the mean water depth. Here $\sigma$ varies from 0 (surface) to -1 (bottom). A uniform grid is used in $\sigma$, with vertical resolution $\Delta \sigma=0.017$ (61 points in the vertical). This resolution corresponds to a maximum vertical $\Delta z$ of $5 \mathrm{~m}$ off the bank and $0.67 \mathrm{~m}$ on the top of the bank. A non-uniform horizontal grid is used in the cross-bank direction. The horizontal $\Delta x$ is $500 \mathrm{~m}$ near and across the bank and increases linearly over an interval of 30 grid points to $11.96 \mathrm{~km}$ outside the immediate domain. The time step is $110.4 \mathrm{~s}$, corresponding to 405 time steps over a $M_{2}$ (12.42 hr) tidal cycle.

[9] To focus on the dynamics and kinematics associated with the tidal-mixing front on the southern flank, configuration of the model was modified by removing the northern flank from the numerical domain. The new configuration features a cross-isobath section with water depth varying from $100 \mathrm{~m}$ on the southern flank to $36 \mathrm{~m}$ on the top of the bank (Figure 4). This numerical domain is extended about $250 \mathrm{~km}$ northward and southward with depths of 36 and $100 \mathrm{~m}$, respectively. A $\mathrm{M}_{2}$ tidal forcing is specified at the southern open boundary, and a gravity wave radiation condition is applied at the northern open boundary.

[10] The advantages of this simplification are (1) to allow the observed CTD data to be easily incorporated into the model, and (2) to avoid internal wave reflections on the northern open boundary. The 15 June 1999 CTD tempera- ture and salinity fields (Figure 2) were used as initial conditions for the model. Since the CTD transect did not cover the entire computational domain, temperature and salinity at the first and last sites of the measurement transect were extended uniformly toward the southern and northern boundaries.

[11] The model was run with $\mathrm{M}_{2}$ tidal forcing for 20 tidal cycles, until the tidal and residual flows reached a quasiequilibrium state (when the change of the residual velocity is 1 order of magnitude smaller than the total residual velocity). Then, the measured wind and/or archived surface heat flux were/was added to examine their roles in the crossfrontal transport. The numerical experiments consisted of several process studies: (1) a constant wind stress averaged over 7 days (15-22 June); (2) wind stress calculated from the winds measured on board R/V Edwin Link during 1522 June 1999 (Figure 3, top panel); and (3) wind stress plus archived surface heat flux. The surface heat flux used in this study was specified based on the June 1995 measurements from the U.S. GLOBEC Stratification Study central buoy (ST1) on the southern flank [Beardsley et al., 2003] since concurrent data in 1999 were not available (Figure 3, bottom panel). Following Simpson and Dickey [1981], the downward shortwave flux in the ocean was approximated by

$$
S W(z, t)=S W(0, t)\left[\operatorname{Re}^{\frac{z}{a}}+(1-R) e^{\frac{z}{b}}\right],
$$

where $S W(0, t)$ is the net shortwave flux incident at the surface, $a$ and $b$ are attenuation lengths for longer and shorter (blue-green) wavelength components of the shortwave irradiance, and $R$ is the percent of the total flux
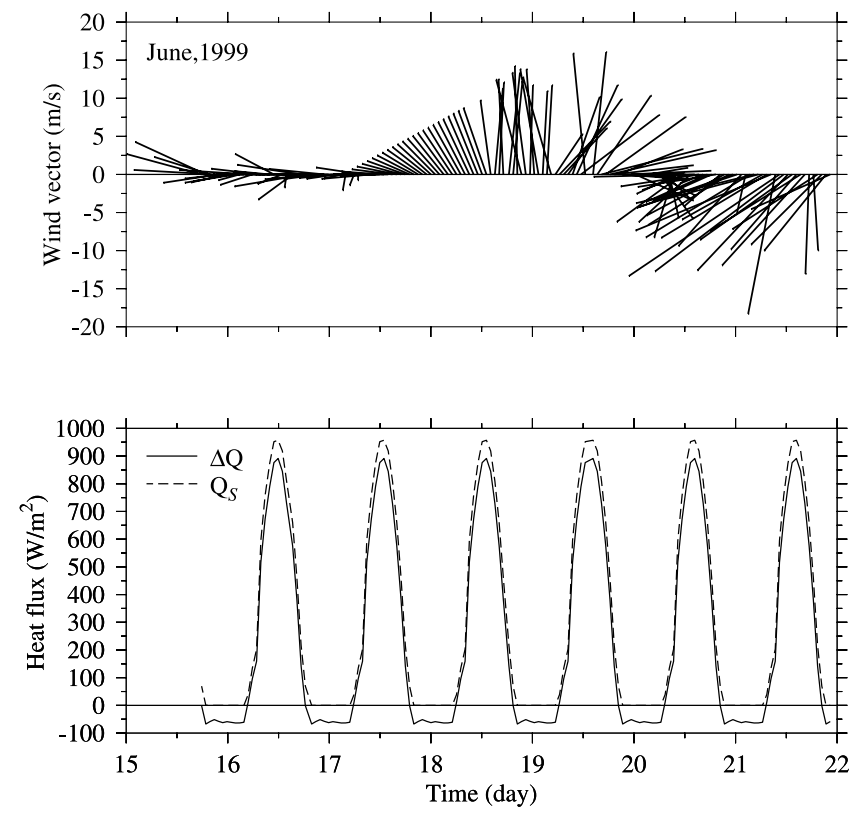

Figure 3. Wind vectors recorded on $\mathrm{R} / \mathrm{V}$ Edwin Link between 15 and 22 June 1999 at the tidal-mixing front on the southern flank of Georges Bank (upper) and downward shortwave radiative flux $Q_{s}$ (dashed line) and net heat flux $\Delta Q$ (solid line) measured on the southern flank during June 1995. Linear interpolation was used to fill the gap in the wind record during June 17-19 1999. 

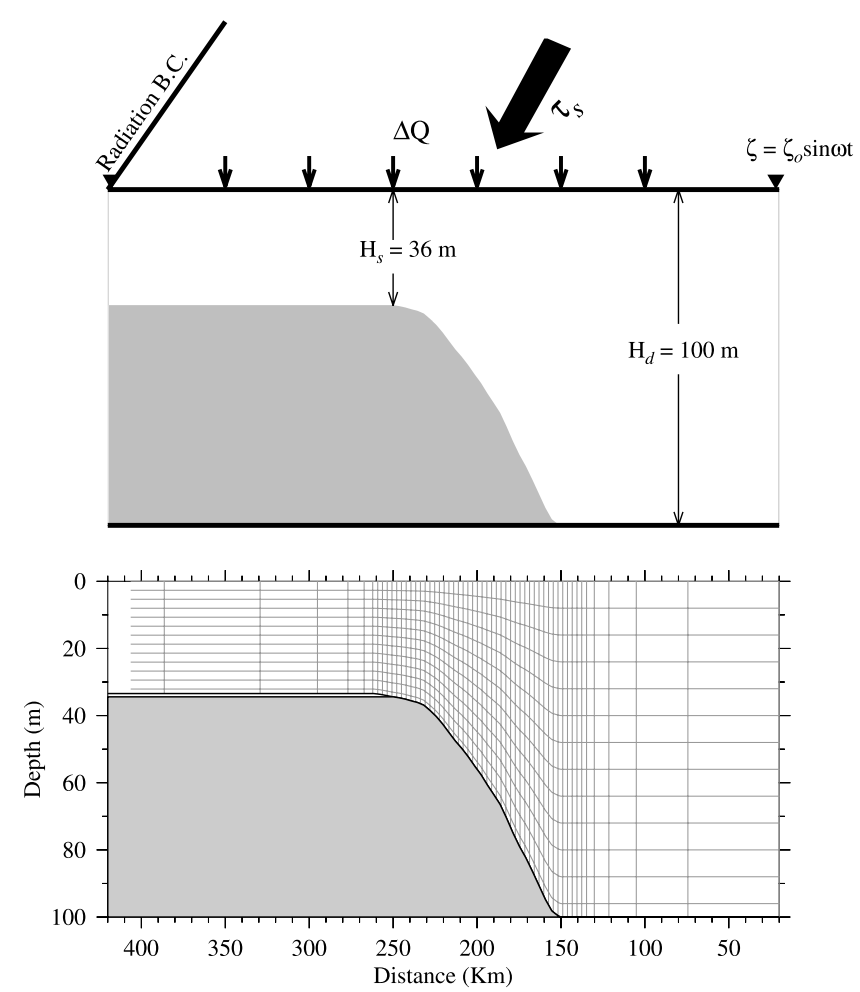

Figure 4. (top) Schematic of the 2D model and (bottom) numerical grid. The grid was plotted using every fourth point in the vertical and tenth point in the horizontal.

associated with the longer wavelength irradiance. We used the following values appropriate for $\mathrm{GB}: R=0.78, a=$ $1.4 \mathrm{~m}$, and $b=6.3 \mathrm{~m}$ [see Chen et al., 2003b]. Although these data do not represent the actual conditions during June 1999, they are sufficient for a mechanistic study on the impact of the diurnal heat flux on the temporal variation of the front and cross-frontal transport of water.

[12] To examine the contributions of advection and mixing to the cross-frontal water transport, particles were released in the stratified region and then traced under different flow fields with or without inclusion of (random walk) vertical mixing. For the case without vertical mixing, particle trajectories were calculated by solving the $\mathrm{x}$ and $\mathrm{z}$ equations for velocity

$$
\frac{d x}{d t}=u, \frac{d \sigma}{d t}=\frac{\varpi}{H+\zeta}
$$

where $u$ and $\varpi$ are the $x$ and $\sigma$ components of water velocity, respectively. The relation between $\varpi$ and $w$ is defined as

$$
\varpi=w-(1+\sigma) \frac{d \zeta}{d t}-\sigma \frac{d H}{d t},
$$

where $w$ is the vertical velocity in the $z$ coordinate direction [Chen and Beardsley, 1998]. Particle velocities were obtained using a bilinear interpolation from the four nearest grid points, and then particle trajectories calculated by means of a fourth-order Runge-Kutta scheme with a truncation error of order $(\Delta t)^{5}$ where $\Delta t$ is the time step for numerical integration.
[13] For the case with vertical mixing, a vertical motion due to random walk is added to the fluid velocity at each time step. In this case, the vertical displacement of a particle is calculated by solving the modified $\sigma$-equation for velocity

$$
\frac{d \sigma}{d t}=\frac{\varpi+\omega^{\prime}}{H+\zeta}
$$

where $\omega^{\prime}$ is the turbulent vertical velocity defined in numerical form by

$$
\omega_{n+1}^{\prime}=a_{n} \omega_{n}^{\prime}+b_{n} \hat{\sigma}_{\omega n} \xi_{n}+C_{n},
$$

where $n$ and $n+1$ are the $n$-th and $(n+1)$-th time steps, $a_{n}=$ $\exp \left(-\Delta t / \tau_{1 n}\right) \quad b_{n}=\left[1-\exp \left(-2 \Delta t / \tau_{1 n}\right)\right]^{1 / 2}, \quad \hat{\sigma}_{\omega}^{2}$ is the Lagrangian velocity variance and its value at $n$-th time step is $\hat{\sigma}_{\omega n}^{2}=0.3 q_{n}^{2} / 2, \xi_{n}$ is the $n$-th time step Gaussian noise with zero mean, $C_{n}=F \tau_{1 n}\left[1-\exp \left(-\Delta t / \tau_{1 n}\right)\right], F=\partial\left(\sigma_{\omega}^{2}\right) / \partial z$, $\tau_{1 n}=\left(K_{m} / \hat{\sigma}_{\omega}^{2}\right)_{n}$ is the Lagrangian integral timescale, $K_{m}$ is the vertical eddy viscosity, and $q^{2} / 2$ is the turbulent kinetic energy.

[14] This random walk vertical velocity was derived based on a Markov equation for vertical velocity of a particle in inhomogeneous turbulence by Legg and Raupach [1982], first introduced to Lagrangian particle tracking in the Gulf of Maine/GB by Hannah et al. [1998]. The numerical method used here requires that $\Delta t<\tau_{1}$. This condition avoids unrealistic aggregation of particles in inhomogeneous turbulent fields [Hannah et al., 1998].

[15] The advantage of tracking particles in fluid fields with or without the inclusion of vertical random walk is to distinguish various physical processes influencing crossfrontal transport of water and particles without needlessly complicating the description of these processes. Since the random walk of a particle depends on the Lagrangian integral timescale defined as the ratio of vertical eddy viscosity to the Lagrangian velocity variance, its influence on a particle trajectory should be less in a stratified region than in a mixed region. Comparisons between particle trajectories computed for these two cases have given a qualitative insight into the role of vertical mixing in the cross-frontal transport on the southern flank of GB.

\section{Model Results}

\subsection{Case 1: Tidal Forcing Only}

[16] With only tidal forcing, the model-predicted residual flow field shows a southwestward current jet in the alongbank direction and double circulation cells in the cross-bank direction within and north of the tidal-mixing front on the southern flank (Figure 5). The current jet has a maximum speed of about $12 \mathrm{~cm} / \mathrm{s}$ at a subsurface depth of $12-15 \mathrm{~m}$, a location where temperature and salinity isopleths split upward and downward. An upward flow is found at the center of the front, just shoreward of the maximum core of the along-bank jet. This results in two secondary circulation cells with divergence near the surface at the northern boundary of the temperature and salinity outcrops and less distinct convergence near the bottom within the frontal zone where the relatively strong upward flow occurred. The water tends to converge toward the on-bank edge of the tidal-mixing front in the upper $15 \mathrm{~m}$ and then re-circulate 

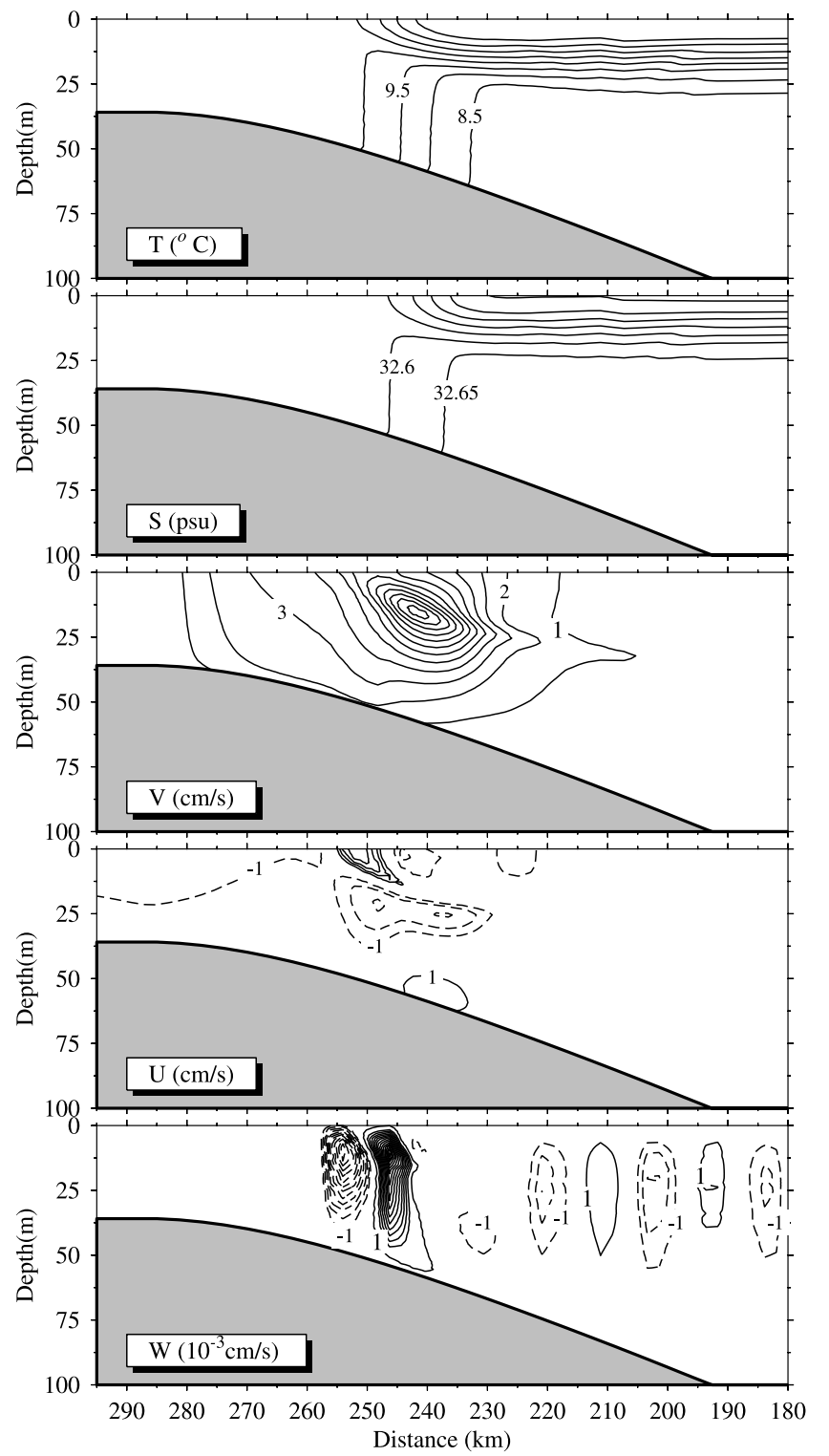

Figure 5. Model-computed cross-isobath distributions of tidally averaged temperature $(\mathrm{T})$, salinity $(\mathrm{S})$, and along-bank (V: positive toward the southwest), cross-bank (U: positive on-bank), and vertical (W: positive upward) velocities on the southern flank.

back in the deeper region. This depiction of secondary circulation is very similar to that suggested using the semi-analytical diagnostic frontal model of Garrett and Loder [1981] (shown here in Figure 6).

[17] In this case, particles, which initially were vertically uniformly within the frontal zone, move on-bank near the bottom, and off-bank both above the bottom boundary layer and below the base of the thermocline. The particles in the thermocline and surface mixed layer also tend to move offbank, but slowly as a result of the off-bank retreat of the front. This is due to gradual off-bank development of the tidal mixed region (Figure 7). There is no tendency for crossfrontal movement of particles except those near the bottom, which move on-bank with a speed of about $0.5 \mathrm{~cm} / \mathrm{s}$. At this speed, it would take about 20 days for particles released near the bottom at a location $10 \mathrm{~km}$ away from the on-bank edge of the tidal-mixing front to enter the frontal mixing region. Considering a recirculation timescale of 50 days around GB [Limeburner and Beardsley, 1996; Naimie et al., 2001; Chen et al., 2002], these bottom particles would have already moved from the southern flank, potentially around to the northern flank before crossing the front. Therefore no significant cross-frontal transport of water is expected in periods of $2-10$ days (the synoptic weather band) if the $\mathrm{M}_{2}$ tide is the only external forcing causing the migration of the frontal location and mixing.

\subsection{Case 2: Tidal Plus Wind-Forcing}

[18] During the June 1999 period corresponding to the observations, the wind blew westward for the first 3 days, turned clockwise and blew northward for the next 3 days, and then southwestward for 2 days (Figure 3, top panel). The wind stress averaged over 15-22 June was 0.19 dyne $/ \mathrm{cm}^{2}$ directed toward $194^{\circ}$ clockwise from the on-bank direction $\left(330^{\circ}\right.$ measured clockwise from true north). When the model is forced with the tide and average wind stress, particles
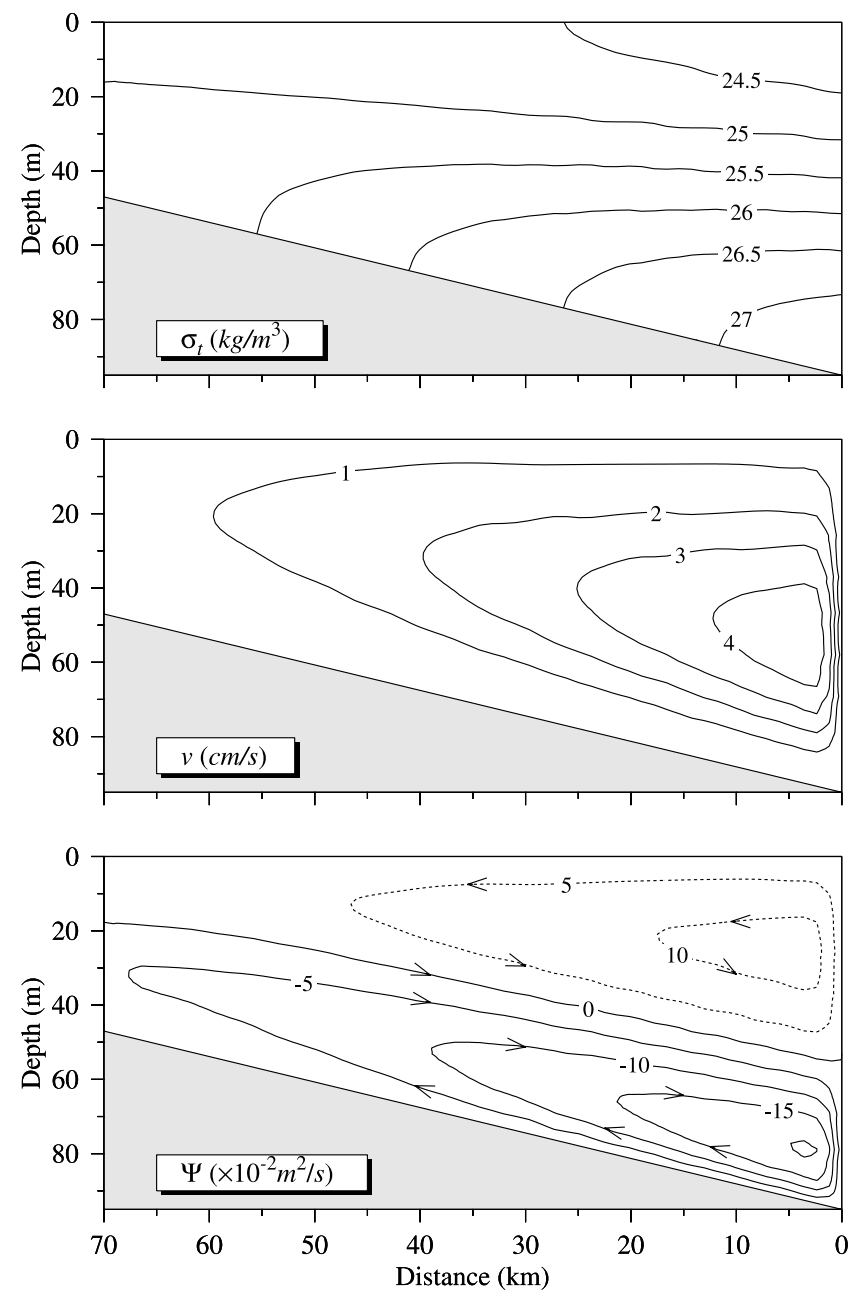

Figure 6. Across-isobath distributions of density, alongisobath current, and cross-isobath stream function calculated using the diagnostic frontal model of Garrett and Loder [1981]. 

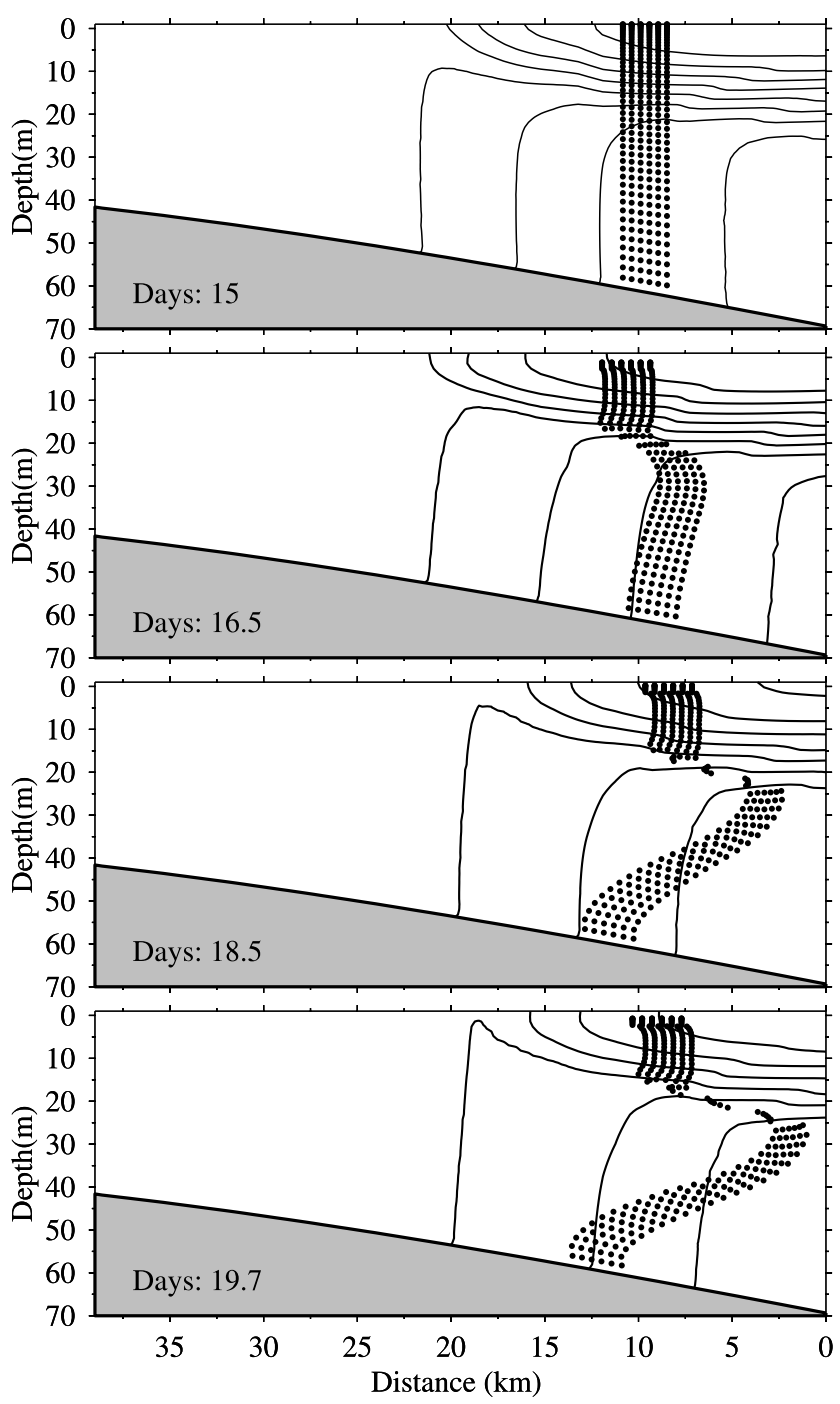

Figure 7. Distribution of particles at the model days 15 (initial positions), $16.5,18.5$, and 19.7 for the case with tidal forcing only (model time starts on 15 June 1999). The contours are the model-computed temperatures for all succeeding figures.

released within the upper $8 \mathrm{~m}$ of the water column move onbank at about $0.2 \mathrm{~cm} / \mathrm{s}$. Considering a weekly timescale, no significant cross-frontal transport would occur, even though the front still tends to retreat off-bank as a result of wind plus tidal mixing (Figure 8).

[19] For the case with tidal forcing and time-dependent wind stress, a clear on-bank intrusion of stratified water within the upper $10 \mathrm{~m}$ occurred in the first 2 days (Figure 9). This was a result of the on-bank Ekman flux driven by the westward wind stress. The particles near the surface moved on-bank along with the signature of the thermal front. When the wind decreased in speed and turned northward on 19 June, the water became vertically mixed again in the region shallower than $50 \mathrm{~m}$. As a result, particles, which were carried on-bank along with the intrusion of the thermal front, remained in the well-mixed region. This indicates that a significant fraction of the particles originally above the recently formed thermocline could be moved into the wellmixed region on timescales of a few days by combined wind-induced advection and tidal mixing.

\subsection{Case 3: Tidal Plus Wind-Forcing and Heat Flux}

[20] The cross-frontal movement of particles is further enhanced when the surface heat flux is added (Figure 10). For a given time-dependent wind stress shown in Figure 9, the actual Ekman transport is the same in both cases with and without surface heating. However, adding heat flux increases the stratification, making the surface mixed layer thinner and thus increasing the near-surface, on-bank velocity. This causes the front to be advected faster in the cross-frontal direction. Since particles were released uniformly in the vertical, the thinner layer initially carries fewer particles. Because the layer moves farther (at a higher speed) and particles in the thermocline also are carried on-bank along with the movement of the thinner mixed layer, tidal mixing causes more particles to be retained in the well-mixed region after the thinner mixed layer is vertically well mixed during the wind relaxation.

\subsection{Case 4: Tidal Plus Wind-Forcing and Random Walk Dispersion}

[21] Stochastic or random walk models of particle trajectories have been widely used to examine the dispersion of passive tracers in highly turbulent fluids [Legg and Raupach, 1982; Thomson, 1987]. To examine the effect of vertical diffusion on the cross-frontal particle transport on
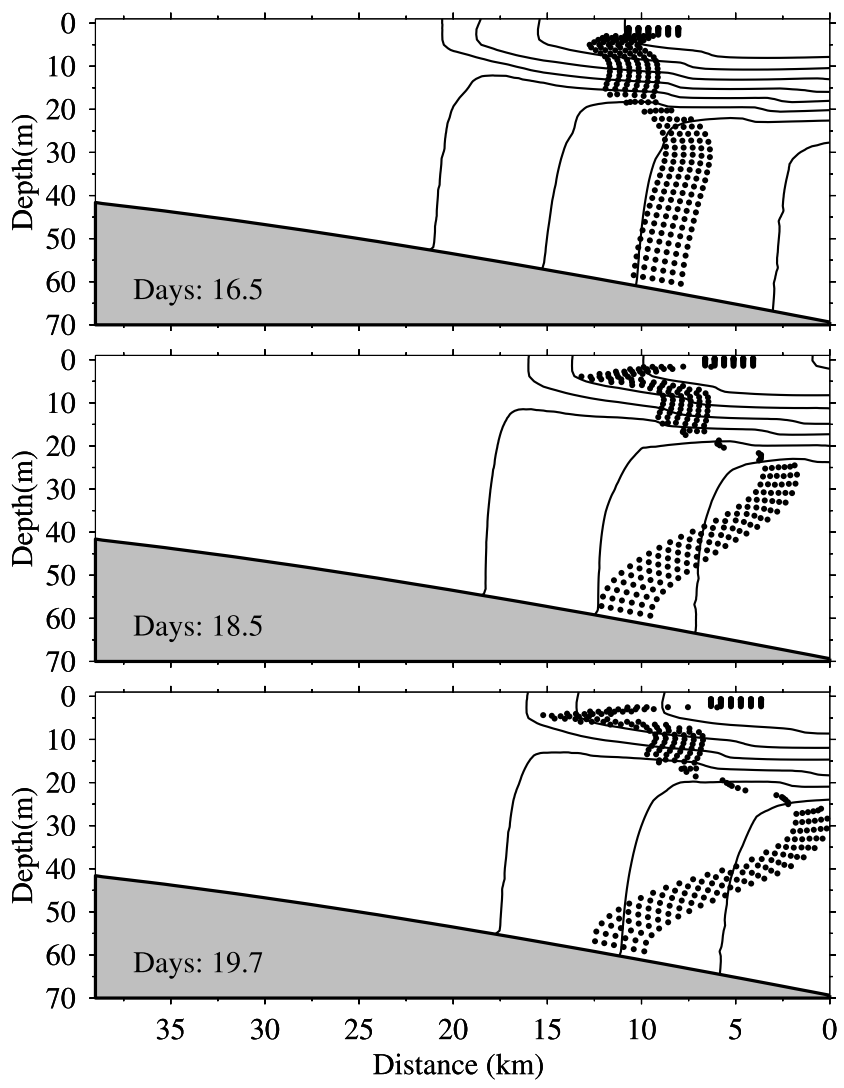

Figure 8. Distribution of particles at model days 16.5, 18.5 , and 19.7 for the case with tidal forcing plus the timeaveraged wind stress. 


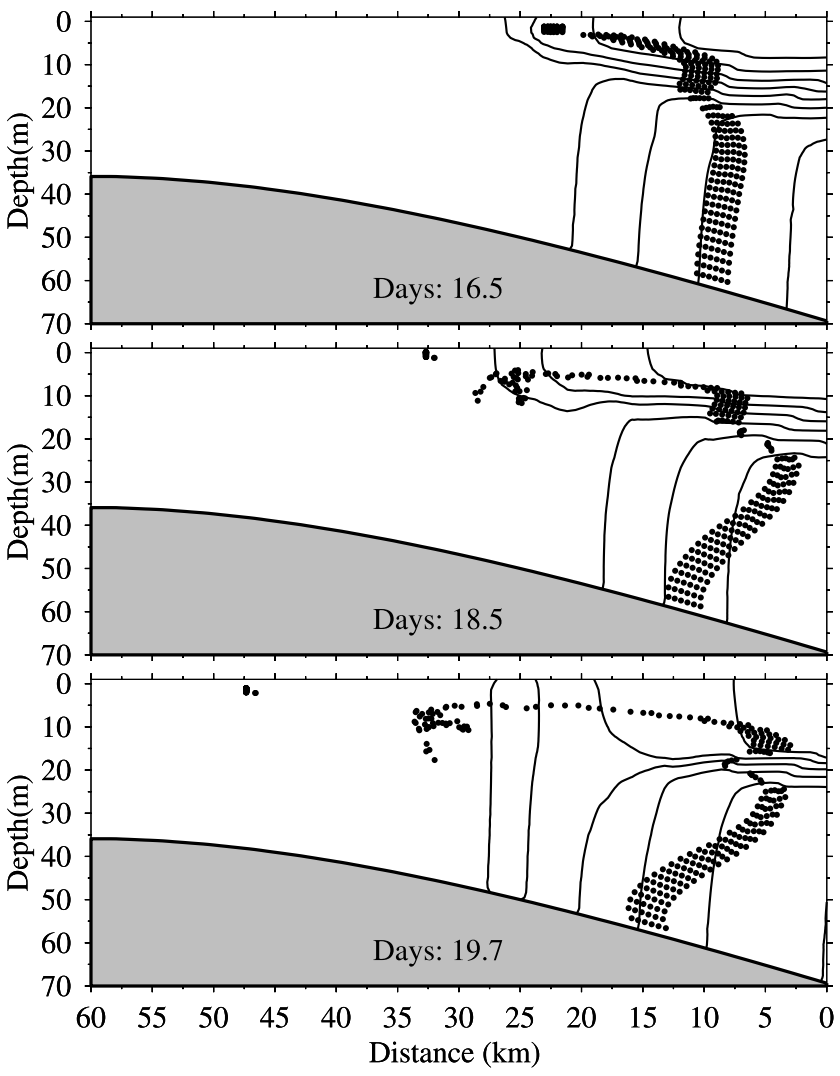

Figure 9. Distribution of particles at model days 16.5, 18.5, and 19.7 for the case with tidal forcing plus realistic wind stress.

the southern flank of GB, the vertical random walk turbulent velocity (described in equation (5)) was included in particle tracking for the case with tidal forcing and timedependent wind stress.

[22] The time step used for the vertical random walk was chosen to satisfy the requirement $\Delta t<\tau_{1}$. On the southern flank of GB, in the thermocline, $\hat{\sigma}_{\omega}<0.4 \times 10^{-2} \mathrm{~m} / \mathrm{s}$ (for $q^{2}<10^{-4} \mathrm{~m}^{2} / \mathrm{s}^{2}$ ) and $\tau_{1} \sim 6.3 \mathrm{~s}$ (for $K_{m} \sim 10^{-4} \mathrm{~m}^{2} / \mathrm{s}$ ). In the bottom mixed layer beneath the main thermocline, $\hat{\sigma}_{\omega} \sim$ $0.4 \times 10^{-2}-1.2 \times 10^{-2} \mathrm{~m} / \mathrm{s}\left(\right.$ for $\left.q^{2} \sim 10^{-4}-9 \times 10^{-4} \mathrm{~m}^{2} / \mathrm{s}^{2}\right)$ and $\tau_{1} \sim 600-1700 \mathrm{~s}$ (for $K_{m} \sim 0.01-0.04 \mathrm{~m}^{2} / \mathrm{s}$ ). In the mixed region on the top of GB, $\hat{\sigma}_{\omega} \sim 0.8 \times 10^{-2}-2.7 \times$ $10^{-2} \mathrm{~m} / \mathrm{s}$ (for $q^{2} \sim 5 \times 10^{-3} \mathrm{~m}^{2} / \mathrm{s}^{2}$ ) and $\tau_{1} \sim 93-1600 \mathrm{~s}$ (for $K_{m} \sim 0.01-0.07 \mathrm{~m}^{2} / \mathrm{s}$ ). $\Delta t=5.52 \mathrm{~s}$ was chosen for particle tracking, which is less than the minimum value of $\tau_{1}$ in the main thermocline and corresponds to 8100 time steps over the $M_{2}$ tidal cycle.

[23] As in the case with tidal forcing plus variable windforcing, particles were released uniformly on 15 June about $8 \mathrm{~km}$ from the on-bank edge of the tidal-mixing front on the southern flank. Unlike those shown in Figure 9, particles with vertical random walk tend to move into the main thermocline during the first 2 days, even though they show some on-bank movement during the westward wind (Figure 11). When the wind relaxed on 19 June, particles diffused upward and downward within the frontal zone as the stratification weakened due to tidal mixing. This particle dispersion process continued as the front moved on-bank during the southwestward wind stress on 20 June. As a result, significantly fewer particles were found on the well mixed side of the front than in the case without vertical random walk. This result is consistent with the results of an in situ dye experiment by Houghton and Ho [2001] and a passive tracer numerical experiment by Chen et al. [2003b]. Both experiments suggest that vertical mixing tends to reduce the cross-frontal water transport on the southern flank of GB.

[24] It should be pointed out that particle displacements in the case with vertical random walk are sensitive to the time step; that is, different choices of $\Delta t<\tau_{1}$ could lead to quite different particle trajectories. As shown in Figure 11, particles tend to aggregate in the low diffusive thermocline region in the first couple of days. This result seems unrealistic because there is no physical mechanism for accumulation of particles in low-diffusivity regions under vertical random walk [Thomson, 1987; Holloway, 1994]. Many previous studies suggest that the cause is incorrect random walk models [e.g., Visser, 1997]. The influence of vertical diffusion on particle displacements in the strong tidal and surface forcing conditions found on the southern flank of GB needs to be re-examined with careful experiments using corrective statistical and kinematic random walk approaches.

[25] Random walk due to horizontal diffusion was not considered in this study. In general, the horizontal random displacements of particles can be estimated for a normal distribution when horizontal diffusion is known [Hannah et al., 1998]. A constant horizontal diffusivity of $20 \mathrm{~m}^{2} / \mathrm{s}$ was
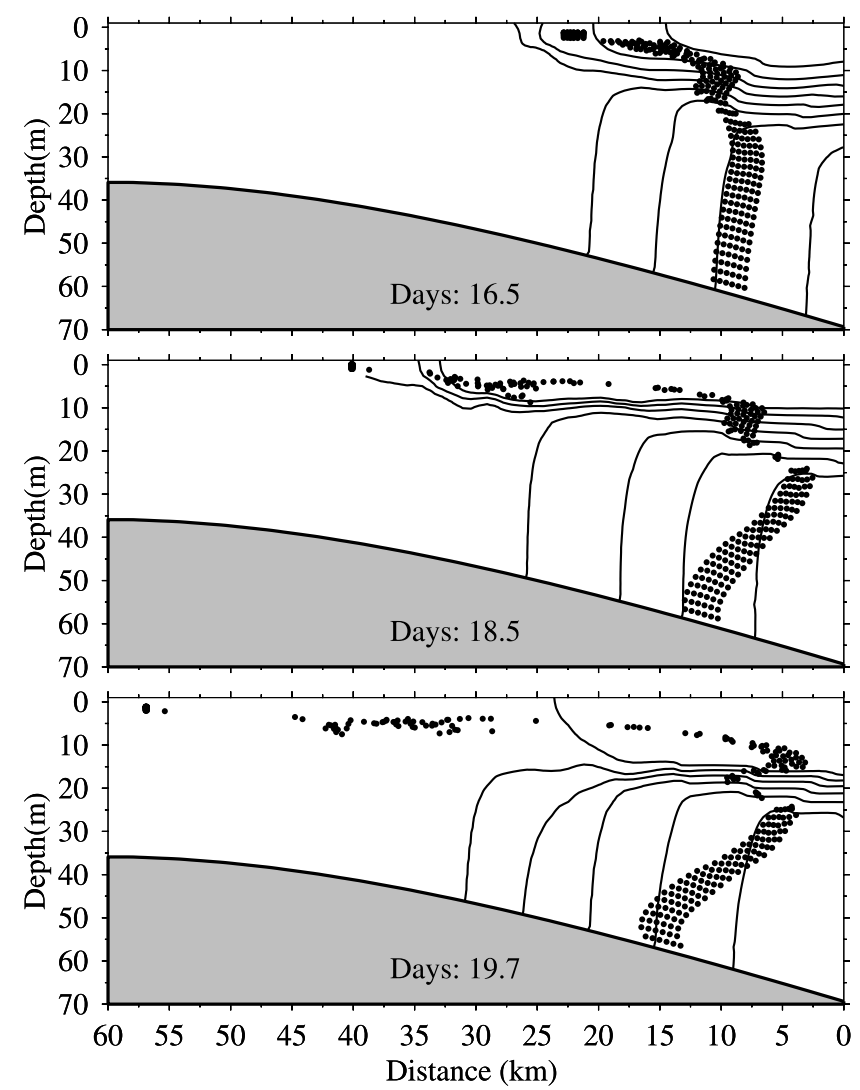

Figure 10. Distribution of particles at model days 16.5, 18.5, and 19.7 for the case with tidal forcing, realistic wind stress, and surface heat flux. 

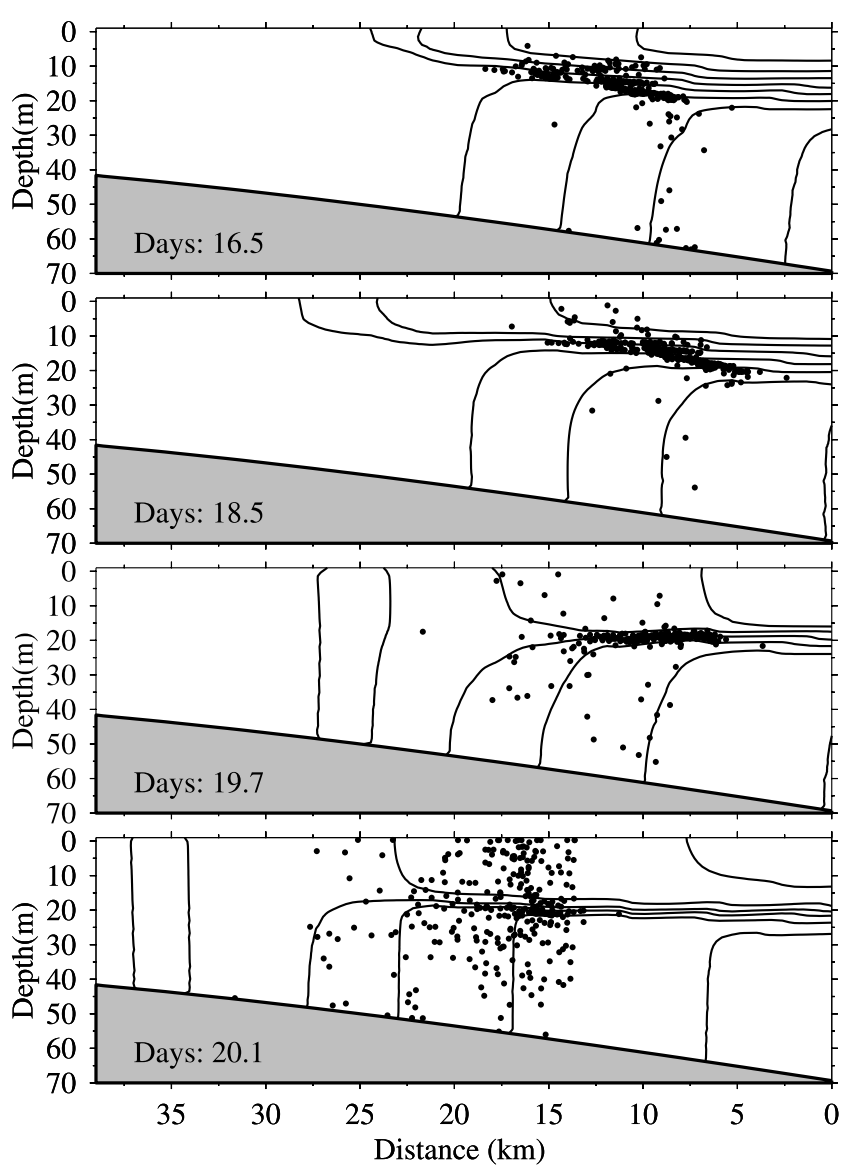

Figure 11. Distribution of particles at model days 16.5, $18.5,19.7$, and 20.1 for the case with tidal forcing, realistic wind stress, and vertical random walk. Note the change of horizontal scale.

used in these modeling experiments, a value used before in studies of stratified tidal rectification. The corresponding horizontal diffusive scale is only $\sim 3 \mathrm{~km}$ in 5 days, so that this process does not contribute significantly to the particle trajectories in the present modeling experiments.

\section{Discussion}

[26] What has been learned from these 2D modeling experiments? Since particle trajectories in the case with vertical random walk are more dependent on the choice of time step, our model results in this case must be considered with caution. However, for the purely advective cases without vertical random walk, the following results are both informative and more solid.

[27] First, the cross-frontal flux of water on the southern flank of GB cannot be simply estimated as a steady state Ekman transport because both the location of the front and particles near the surface are advected at the same speed due to wind-induced Ekman transport. Since deformation of the frontal boundary is due solely to the Ekman transport, crossfrontal transport of water cannot occur in a short time period without tidal mixing.
[28] Second, time-varying wind stress and continuous tidal mixing are key concurrent physical processes that can cause considerable cross-frontal transport of water in the upper mixed layer. Westward wind stress associated with storms or passages of meteorological fronts causes an on-bank advection of particles, and tidal mixing traps them in the wellmixed region after the wind relaxes. Inclusion of positive heat flux at the surface tends to reduce the thickness of the mixed layer, and enhances the cross-frontal transfer of particles (note: the idealized case presented here represents the maximum effect since actual heat flux could be reduced due to clouds or fogs). In summary, on the basis of measured surface forcing for early summer on the southern flank of GB, no significant cross-frontal movement of particles would occur within the weather band without the combined forcing of wind stress and tidal mixing.

[29] Physical mechanisms responsible for cross-frontal transport of water received intense attention in the U.S. GLOBEC Phase III 1999 field program due to the hypothesized importance of physical controls on biological distributions. Previous modeling studies show that cross-frontal transport could occur due to strongly nonlinear tidal interaction [Loder et al., 1997; Chen et al., 2003a]; asymmetric tidal mixing [Chen and Beardsley, 1998; Pringle and Franks, 2001], baroclinic eddy instability [Pingree, 1979; Garrett and Loder, 1981], and chaotic mixing due to the periodic on/ off-bank movement of the tidal-mixing front [Chen and Beardsley, 2002]. Other cross-frontal processes caused by wind-forcing [Lewis et al., 2001] provide alternative mechanisms for the cross-frontal transport of biota in early summer.

[30] Relative importance of these processes varies with location and time. On the northern flank, in the horizontal plane, strongly nonlinear tidal currents over the steep bottom slope result in a large Stokes' drift. Hence, the Lagrangian residual currents are generally $40-50 \%$ weaker than the mean Eulerian currents [Loder et al., 1997]. Particles there tend to flow onto the bank following three major paths: at the northwestern edge, between the $40-60 \mathrm{~m}$ isobaths, and also around 100-m isobath [Limeburner and Beardsley, 1996; Chen et al., 2003a]. These Lagrangian flows could carry considerable water from the stratified region along the northern edge into the mixed region. In the vertical, interaction of strong tidal currents with steep bottom topography produces a large vertical tidal excursion and hence leads to a mean upward Lagrangian motion near the bottom [Chen and Beardsley, 1998; Chen et al., 2003a]. This process can also cause significant near-bottom crossfrontal transport [Pringle and Franks, 2001].

[31] On the southern flank, due to the gentle bottom slope, Lagrangian currents are much weaker than those found on the northern flank. Water tends to converge toward the tidalmixing front near the bottom, which, to some extent, tends to restrict cross-frontal on-bank transport [Houghton and Ho, 2001]. Also, since the mean on-bank Lagrangian velocity is generally about $1-2 \mathrm{~cm} / \mathrm{s}$, it would take at least a week for particles to cross the zone of the tidal-mixing front from the stratified side to the mixed side [Chen et al., 2003a]. Therefore, considering only tidal-induced cross-frontal transport on GB, the northern flank acts as a source, but the southern flank between the shelfbreak front and tidal-mixing front is more like a retention zone. 
[32] In early summer, although the mean wind speed on GB is only about $3 \mathrm{~m} \mathrm{~s}^{-1}$, the wind varies over the synoptic (2-10 day) weather band as a result of the passage of storms and atmospheric fronts. Since the water column is characterized by a weak thermocline (pycnocline) in the upper $20 \mathrm{~m}$ during this period, the structure of the tidal-mixing front is in a relatively unstable condition. An on-bank migration of the front can occur in the upper 10-20 m over a short period of time (1-2 days) as a result of a wind-induced on-bank Ekman transport. Since the vertical gradient of temperature decreases during the on-bank movement of the front, the onbank intrusion of near-surface water can be vertically mixed quickly due to the stronger tidal currents in shallower water as the wind relaxes or shifts (Figure 12).

[33] Seasonal stratification on the southern flank of GB can vertically structure residing plankton populations (Figure 13) [Lough and Mountain, 1996; Smith and Morse, 1985; Townsend and Pettigrew, 1996]. In late May/June, the late stages of Calanus finmarchicus and Pseudocalanus spp. can be very concentrated near the surface above the thermocline [Norrbin et al., 1996] as well as their nauplii [Lough et al., 1994]. The adults and late stage copepodites of the copepods Calanus finmarchicus, Pseudocalanus spp., Centropages typicus, and Centropages hamatus are dominant species found on GB [Kane, 1993]. Calanus finmarchicus and Pseudocalanus spp. both dominate the zooplankton community in early and late spring and decline during summer. C. typicus increases in abundances until it peaks in the autumn. C. hamatus is almost entirely restricted to the shoal region of GB and peaks in population numbers during the summer months. The three sibling species of Pseudocalanus, P. moultoni, and P. newmani differ in their spatial distributions and peak abundances [Bucklin et al., 2001]. P. moultoni adult females are always more abundant on the crest of the bank in the spring which may result from their retention of reproducing females and/or transport from adjacent regions. Fish eggs and early larvae also can be concentrated within or above the thermocline in stratified water, while older larvae undergo diel vertical migration.

[34] A recent study by Lough and Manning [2001] near the tidal-mixing front on the southern flank in late May 1999 provides biological evidence for near-bottom cross-frontal transport to the crest of GB on the order of $1 \mathrm{~cm} / \mathrm{s}$. This process is associated with tidal rectification [Chen and Beardsley, 1998; Chen et al., 2003a], which is a continuous process during the winter/spring spawning season of cod and haddock, whereas the wind-induced cross-frontal on-bank water transport described in this paper occurs episodically and only for the near-surface waters above the thermocline. The wind-induced cross-frontal transport mechanism considered here would be less important for the retention of cod and haddock larvae on the crest since most spawning and transport of larvae along the southern flank has already taken place. Retention of certain copepods populations within the shallow mixed region during summer may depend more on the wind-induced transport mechanism.

\section{Conclusion}

[35] The effects of wind and surface heating on the transport of water and particles through the tidal-mixing front on the southern flank of Georges Bank has been

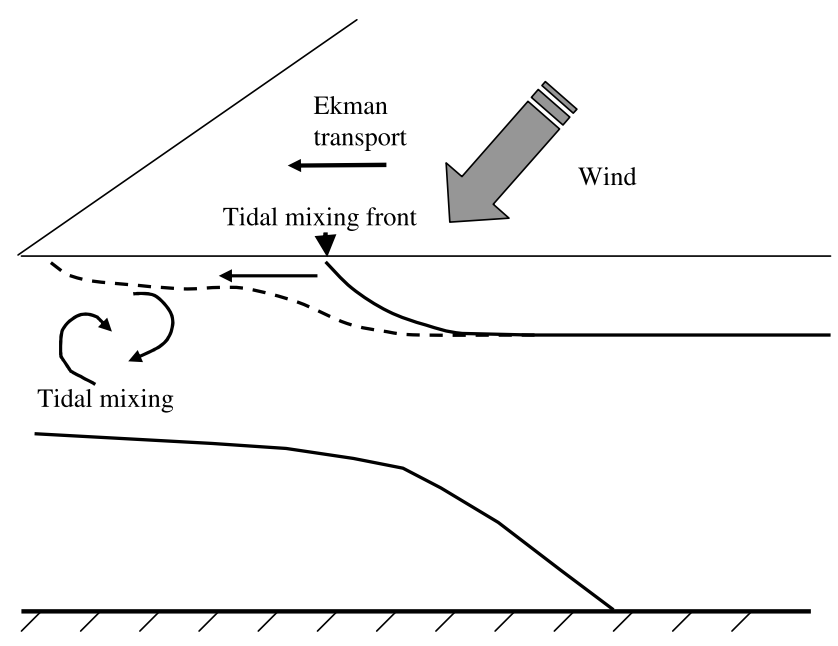

Figure 12. Schematic of the physical mechanism responsible for the wind-induced, cross-frontal particle transport.

examined using a $2 \mathrm{D}$ primitive equation ocean model. The model domain encompasses a CTD section completed on 15 June 1999 across the tidal-mixing front. The model was run prognostically with initialized temperature and salinity conditions observed during the hydrographic survey on 15 June. Five process studies were conducted: tidal forcing; tidal forcing with a mean wind stress; tidal forcing with time-dependent wind stress; tidal forcing with timedependent wind stress and surface heat flux; and tidal forcing with time-dependent wind stress and vertical random walk. For the cases without vertical random walk, the model results show that wind stress fluctuations calculated from measured winds during atmospheric frontal passages can result in a significant cross-frontal, on-bank water transport in the upper $20 \mathrm{~m}$ on GB on timescales of a few days. This process happens in two stages. First, a windinduced on-bank Ekman transport causes an on-bank migration of the upper part of the tidal-mixing front. Although the vertical gradient of water temperature decreases during the bankward migration of the front, all particles still follow the front and little cross-frontal movement occurs. Second, when the wind relaxes or changes direction, the water in the on-bank extended part of the front tends to be quickly mixed by the tidal motion and the front appears to retreat or re-establish off-bank. As a result, particles that are carried along with the front now stay in the mixed region. This on-bank transport of particles is enhanced when surface heating is added.

[36] Particle tracking experiments with vertical random walk show that vertical mixing tends to reduce the crossfrontal transport of particles in the tidal-mixing front on the southern flank of GB. While this result is consistent with in situ dye [Houghton and Ho, 2001] and model passive tracer [Chen et al., 2003a] experiments, additional work is needed to determine quantitatively the influence of vertical diffusion on cross-front particle flux.

[37] These experiments suggest that temporal variations of wind stress play an essential role in the cross-frontal, onbank water transport on the southern flank in early summer when stratification is just developing and a shallow thermocline is forming below the surface. Such a wind-induced 
EL9906, June 1999

1m MOCNESS, haul 295, 6/16/99, 01:18, north slack tide
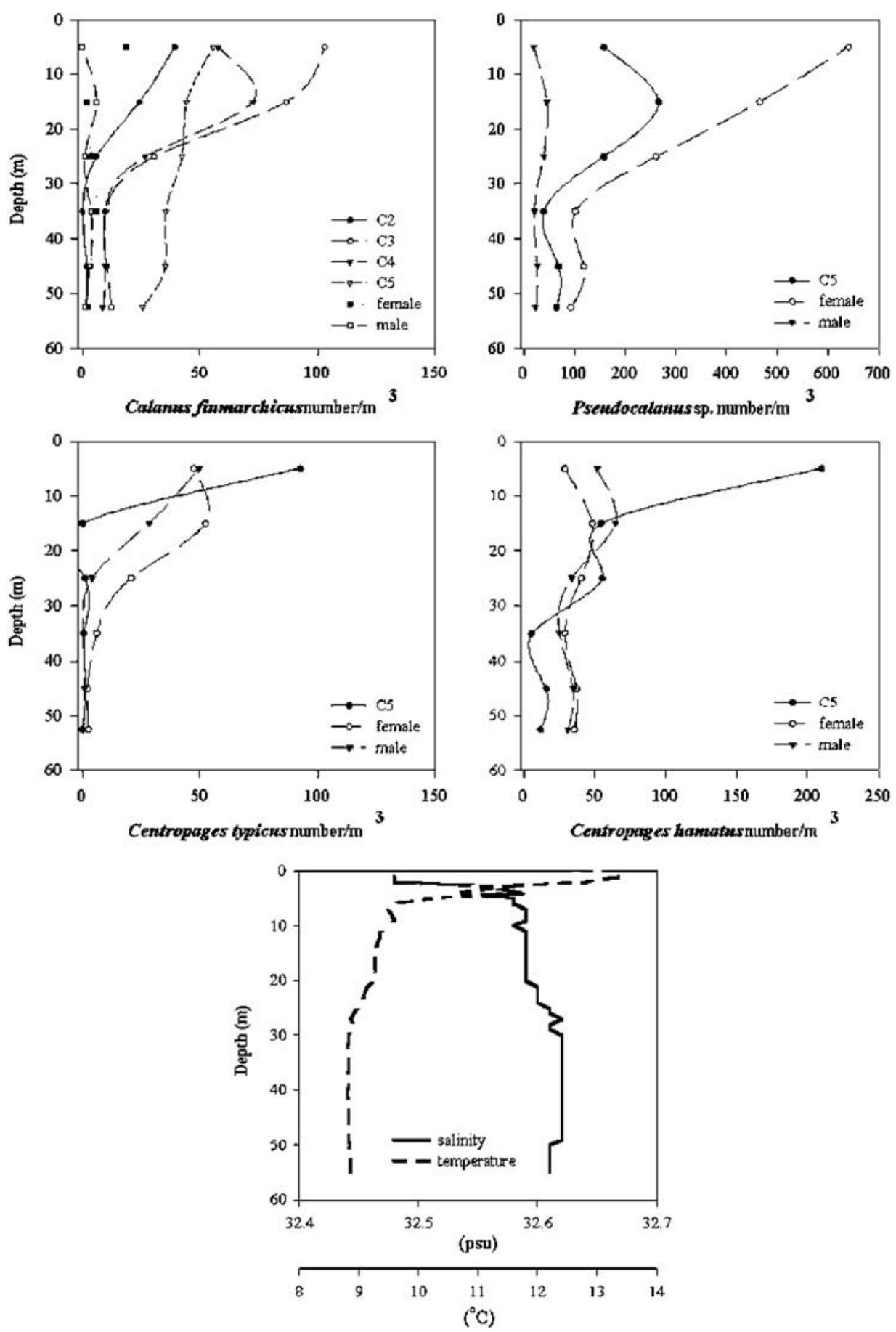

Figure 13. Vertical distributions of copepedite and adult stages of four species of copepods and corresponding temperature and salinity profiles (bottom panel) from $1-\mathrm{m}^{2}$ MOCNESS tow 295 on the southern flank of Georges Bank tidal front, 16 June 1999, 0118 DST, bottom depth $60 \mathrm{~m}, 41^{\circ} 5.5^{\prime} \mathrm{N}$, $67^{\circ} 23.5^{\prime} \mathrm{W}$. Tow profile was nominally $10-\mathrm{m}$ strata to within $5 \mathrm{~m}$ of the bottom. The $1-\mathrm{m}^{2}$ MOCNESS nets typically sampled for $5 \mathrm{~min}$ to filter about $250 \mathrm{~m}^{3}$ of water.

cross-frontal, on-bank water transport occurs intermittently with wind stress fluctuations associated with atmospheric frontal passages. The process can be much larger at short timescales than the tide-induced cross-frontal water flux near the bottom. Thus this wind-induced exchange process could be one of the essential physical processes that cause the cross-frontal, on-bank flux of zooplankton observed on the southern flank of GB in early summer. 
[38] Acknowledgments. This research was supported by the U.S. GLOBEC Northwest Atlantic/Georges Bank program through NOAA grants NA56RG0487, NA960P003, and NA960P005 to C. Chen, NOAA support to R. Schlitz, G. R. Lough, K. Smith, and J. Manning, and NSF grants OCE 96-32357, OCE 98-06379, and OCE 02-27679 to R. Beardsley. We thank Toni Chute who provided the zooplankton identification and analysis, and the comments of two anonymous reviewers. This is U.S. GLOBEC contribution 410 .

\section{References}

Anonymous, U.S. GLOBEC northwest Atlantic implementation plan for the Georges Bank study, Rep. 6, 69 pp., U.S. GLOBEC Steering Comm. Coord. Off., Div. of Environ. Stud., Univ. of Calif., Davis, Davis, Calif., 1992.

Beardsley, R., S. J. Lentz, R. A. Weller, R. Limeburner, J. D. Irish, and J. B. Edson, Surface forcing on the southern flank of Georges Bank, February-August 1995, J. Geophys. Res., 108(C11), 8007, doi:10.1029 2002JC001359, 2003.

Blumberg, A. F., A primer for ECOM-si, technical report, 73 pp., HydroQual, Inc., Mahwah, N. J. 1994.

Bucklin, A., M. Guarnieri, D. J. McGillicuddy, and R. Sean Hill, Springsummer evolution of Pseudocalanus spp. abundance on Georges Bank based on molecular discrimination of P. moultoni and P. newmani, Deep Sea Res., Part II, 48, 589-608, 2001.

Chen, C., and R. C. Beardsley, Numerical study of stratified tidal rectification over finite-amplitude bank: I. Symmetric bank, J. Phys. Oceanogr., $25,2090-2110,1995$.

Chen, C., and R. C. Beardsley, Tidal mixing and cross-frontal particle exchange over a finite amplitude asymmetric bank: A model study with application to Georges Bank, J. Mar. Res., 56, 1165-1201, 1998.

Chen, C., and R. C. Beardsley, Cross-frontal water exchange on Georges Bank: Some results from a U.S. GLOBEC/Georges Bank program mode study, J. Oceanogr., 58, 403-420, 2002.

Chen, C., R. C. Beardsley, and R. Limeburner, Numerical study of stratified tidal rectification over finite-amplitude banks: II. Georges Bank, J. Phys. Oceanogr., 25, 2111-2128, 1995.

Chen, C.. Q. Xu, R. C. Beardsley, and P. J. S. Franks, Model study of the cross-frontal water exchange on Georges Bank: A three-dimensional Lagrangian experiment, J. Geophys. Res., 108(C5), 3142, doi:10.1029/ 2000JC000390, 2003a.

Chen, C., R. C. Beardsley, P. J. S. Franks, and J. Van Keuren, Influences of the diurnally varying heat flux on stratification and residual circulation on Georges Bank, J. Geophys. Res., 108(C11), 8008, doi:10.1029/ 2001JC001245, in press, 2003b.

Franks, P. J. S., and L. J. Walstad, Phytoplankton patches at fronts: A model of formation and response to wind events, J. Mar. Res., 55, 1-29, 1997.

Garrett, C. J. R., and J. W. Loder, Dynamical aspects of shallow sea fronts, Philos. Trans. R. Soc. London, Ser. A, 302, 563-581, 1981.

Hannah, C. G., C. E. Naimie, J. W. Loder, and F. E. Werner, Upper-ocean transport mechanisms from the Gulf of Maine to Georges Bank, with implications for Calanus supply, Cont. Shelf Res., 17, 1911-1988, 1998.

Holloway, G., Comment: On modeling vertical trajectories of phytoplankton in a mixed layer, Deep Sea Res., 41, 957-959, 1994.

Houghton, R. W., and C. Ho, Diapycnal flow through the Georges Bank tidal front: A dye tracer study, Geophys. Res. Lett., 28, 33-36, 2001.

Kane, J., Variability of zooplankton Biomass and dominant species abundance on Georges Bank, 1977-1986, Fish. Bull., 91, 464-474, 1993.

Legg, B. J., and M. R. Raupach, Markov chain simulation of particle dispersion in inhomogeneous flows: The mean drift velocity induced by a gradient in Eulerian velocity variance, Boundary Layer Meteorol., 24, 3-13, 1982.
Lewis, C. V. W., C. Chen, and C. S. Davis, Biological-physical modeling of meroplankton transport and settlement patterns on Georges Bank, Deep Sea Res., Part II, 48, 137-158, 2001

Limeburner, R., and R. C. Beardsley, Near-surface recirculation over Georges Bank, Deep Sea Res., Part II, 43(7-8), 1547-1574, 1996.

Loder, J. W., Y. Shen, and H. Ridderinkhof, Characterization of threedimensional Lagrangian circulation associated with tidal rectification over a submarine bank, J. Phys. Oceanogr., 27, 1729-1742, 1997.

Lough, R. G., and J. P. Manning, Tidal-front entrainment and retention of fish larvae on the southern flank of Georges Bank, Deep Sea Res., Part II, 48, 631-644, 2001

Lough, R. G., and D. G. Mountain, Effect of small-scale turbulence on feeding rates of larval cod and haddock in stratified waters on Georges Bank, Deep Sea Res., Part II, 43, 1745-1772, 1996.

Lough, R. G., W. G. Smith, F. E. Werner, J. W. Loder, F. H. Page, C. G. Hannah, C. E. Naimie, R. I. Perry, M. Sinclair, and D. R. Lynch, Influence of wind-driven advection on interannual variability in cod egg and larval distributions on Georges Bank: 1982 vs. 1985, ICES Mar. Sci. Symp., 198, 356-378, 1994.

Naimie, C. E., R. Limeburner, C. G. Hannah, and R. C. Beardsley, On the geographic and seasonal patterns of the near-surface circulation on Georges Bank-from real and simulated drifters, Deep Sea Res., Part II, $48,501-518,2001$

Norrbin, M. F., C. S. Davis, and S. M. Gallager, Differences in fine-scale structure and composition of zooplankton between mixed and stratified regions of Georges Bank, Deep Sea Res., Part II, 43, 1905-1924, 1996.

Pingree, R. D., Baroclinic eddies bordering the Celtic Sea in late summer, J. Mar. Biol. Assoc. U. K., 54, 689-698, 1979.

Pringle, J. M., and P. J. S. Franks, Asymmetric mixing transport: A horizontal transport mechanism for sinking plankton and sediment in tidal flows, Limnol. Oceanogr., 46, 381-391, 2001.

Simpson, J. J., and T. D. Dickey, The relationship between downward irradiance and upper ocean structure, J. Phys. Oceanogr., 11, 309-323, 1981.

Smith, W., and W. W. Morse, Retention of larval haddock Melanogrammus aeglefinus in the Georges Bank region, a gyre-influenced spawning area, Mar. Ecol. Prog. Ser., 24, 1-13, 1985.

Thomson, D. J., Criteria for the selection of stochastic models of particle trajectories in turbulent flows, J. Fluid Mech., 180, 529-556, 1987.

Townsend, D. W., and N. R. Pettigrew, The role of frontal currents in larval fish transport on Georges Bank, Deep Sea Res., Part II, 43, 1773-1792, 1996.

Visser, A. W., Using random walk models to simulate the vertical distribution of particles in a turbulent water column, Mar. Ecol. Prog. Ser., 17, $275-281,1997$

R. Beardsley, Department of Physical Oceanography, Woods Hole Oceanographic Institution, Woods Hole, MA 02543, USA. (rbeardsley@ whoi.edu)

C. Chen, School of Marine Sciences and Technology, University of Massachusetts-Dartmouth, New Bedford, MA 02744, USA. (c1chen@ umassd.edu)

R. G. Lough, J. P. Manning, and R. J. Schlitz, Northeast Fisheries Sciences Center, Woods Hole, MA 02543, USA. (rschlitz@whsun1.wh. whoi.edu; jmanning@whsun1.wh.whoi.edu; glough@whsun1.wh.whoi. edu)

K. W. Smith, Numerical Methods Laboratory, Thayer School of Engineering, Dartmouth College, Hanover, NH 03755, USA. (keston. smith@dartmouth.edu) 